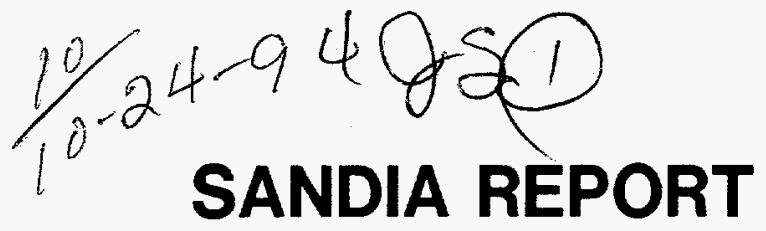

SAND94-0086 - UC-906

Unlimited Release

Printed September 1994

\title{
Discrimination Between NTS Explosions, Earthquakes and the Non-Proliferation Experiment at the Pinedale Seismic Research Facility
}

\section{Dorthe Carr}

\section{Prepared by}

Sandia National Laboratorles

Albuquerque, New Mexico 87185 and Livermore, California 94550

for the United States Department of Energy

under Contract DE-AC04-94AL85000

Approved for public release, distribution is unlimited.
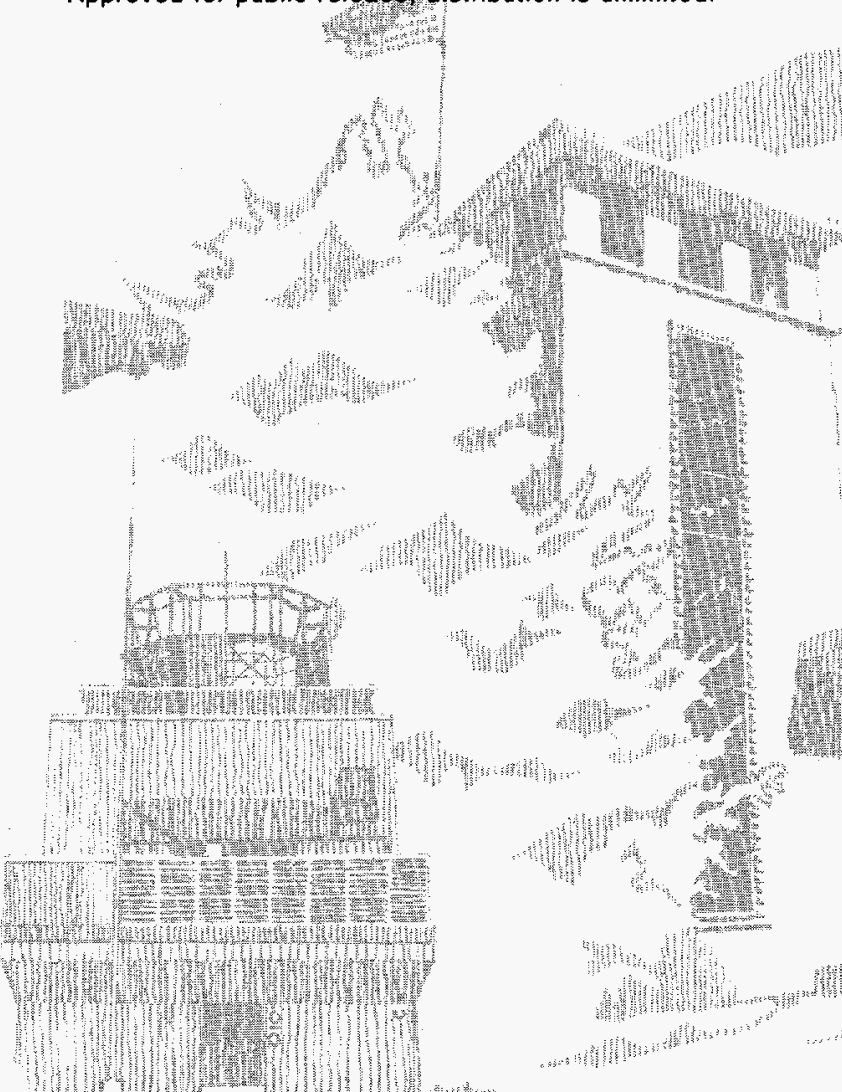
Issued by Sandia National Laboratories, operated for the United States Department of Energy by Sandia Corporation.

NOTICE: This report was prepared as an account of work sponsored by an agency of the United States Government. Neither the United States Government nor any agency thereof, nor any of their employees, nor any of their contractors, subcontractors, or their employees, makes any warranty, express or implied, or assumes any legal liability or responsibility for the accuracy, completeness, or usefulness of any information, apparatus, product, or process disclosed, or represents that its use would not infringe privately owned rights. Reference herein to any specific commercial product, process, or service by trade name, trademark, manufacturer, or otherwise, does not necessarily constitute or imply its endorsement, recommendation, or favoring by the United States Government, any agency thereof or any of their contractors or subcontractors. The views and opinions expressed herein do not necessarily state or reflect those of the United States Government, any agency thereof or any of their contractors.

Printed in the United States of America. This report has been reproduced directly from the best available copy.

Available to DOE and DOE contractors from

Office of Scientific and Technical Information

PO Box 62

Oak Ridge, TN 37831

Prices available from (615) 576-8401, FTS 626-8401

Available to the public from

National Technical Information Service

US Department of Commerce

5285 Port Royal RD

Springfield, VA 22161

NTIS price codes

Printed copy: A03

Microfiche copy: A06 


\section{DISCLAIMER}

Portions of this document may be illegible in electronic image products. Images are produced from the best available original document. 


\title{
Discrimination Between NTS Explosions, Earthquakes and the Non-Proliferation Experiment at the Pinedale Seismic Research Facility
}

\author{
Dorthe Carr \\ Seismic Verification Technology Department \\ Sandia National Laboratories \\ Albuquerque, New Mexico 87185-0655
}

\begin{abstract}
As the United States moves into an atmosphere of concern about the spread of nuclear weapons to non-nuclear countries, the focus on monitoring nuclear explosions is changing from looking at specific test sites and yields to looking for tests of large and small yields from anywhere in the world. Discrimination of small events then becomes important and regional seismic monitoring the best method to detect and identify suspicious events. At the Pinedale Seismic Research Facility (PSRF) in Wyoming we have the opportunity to try different regional discriminants with nuclear tests from NTS, western U. S. (WUS) earthquakes and the Non-Proliferation Experiment (NPE). Four discriminants that gave the best results in a study by Taylor et al. (1989) were tried: $\mathrm{m}_{\mathrm{b}}: \mathrm{M}_{\mathrm{s}}, \mathrm{m}_{\mathrm{b}}: \mathrm{M}_{\mathrm{s}}^{\mathrm{h}}, \log \left(\mathrm{L}_{\mathrm{g}} / \mathrm{P}_{\mathrm{g}}\right)$ and spectral ratios. The different discriminants were applied to the data (14 NTS explosions, the NPE, one Department of Defense (DOD) explosion and 34 WUS earthquakes) regardless of signal-to-noise. When the NTS explosions and NPE were only compared to four earthquakes located on or near the Test Site, all the discriminants except $\log \left(\mathrm{L}_{\mathrm{g}} / \mathrm{P}_{\mathrm{g}}\right)$ worked fairly well at PSRF. When the other WUS earthquakes and DOD explosion are included, only $m_{b}: M_{s}$ shows any promise. Because of frequent physical variations in the earth's crust, regional signals are complex and easily influenced by site and path characteristics. Looking at events from one specific area reduces the effects of the path, which is why three discriminants work well when the data set is restricted to events on or near NTS. The only discriminant not adversely affected from variations in path is $m_{b}$ : $M_{s}$. This is probably because it is believed that source dimension, source time function and/or source mechanism is the cause for the differences between earthquakes and explosions with this discriminant, rather than any path effects.

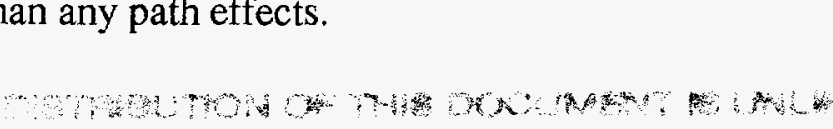




\section{Acknowledgments}

The author thanks Eric Chael and Chris Young for valuable feedback that improved this report. This work was performed at Sandia National Laboratories supported by the U.S. Department of Energy under contract DE-AC04-94AL85000. 
Acronyms and Abbreviations................................................................ vi

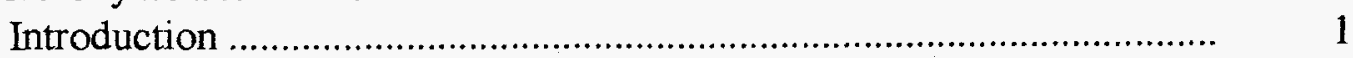

Discrimination Techniques ...................................................................

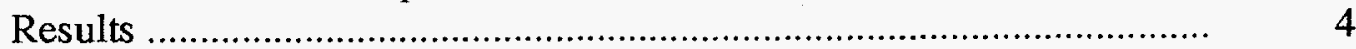

Discussion and Conclusions .................................................................

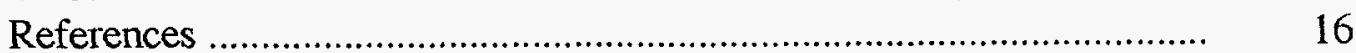

Appendix: List of events used in study .............................................. 18

\section{Figures}

Page

1 Map of PSRF, NTS and WUS earthquakes used in study................ 2

2 The $m_{b}: M_{s}$ discriminant for (a) NTS events only and

(b) all WUS events.

6

3 The $m_{b}: M_{s}^{h}$ discriminant for (a) NTS events only and

(b) all WUS events

4 The $\log \left(\mathrm{L}_{\mathrm{g}} / \mathrm{P}_{\mathrm{g}}\right)$ discriminant for (a) NTS events only and (b) all WUS events..

5 The $\log \left(\mathrm{L}_{\mathrm{g}} / \mathrm{P}_{\mathrm{n}}\right)$ discriminant for (a) NTS events only and (b) all WUS events..

6 The spectral ratio discriminant for (a) NTS events only and (b) all WUS events

7 Two WUS events from Wyoming. Both are considered to be earthquakes, but the top event has more of a characteristic signal of an explosion.

\section{Tables}

1 Pertinent data for NTS explosions, NPE and 4 earthquakes on or near NTS.

2 Pertinent data for other WUS earthquakes and DOD explosion from White Sands. 


\section{Acronyms and Abbreviations}

$\begin{array}{ll}\text { AFTAC } & \text { Air Force Technical Applications Center } \\ \text { CTBT } & \text { Comprehensive Test Ban Treaty } \\ \text { DSVS } & \text { Deployable Seismic Verification System } \\ \text { DOD } & \text { Department of Defense } \\ \text { HF } & \text { high frequency } \\ \text { IP } & \text { intermediate period } \\ \text { LLNL } & \text { Lawrence Livermore National Laboratory } \\ \text { LP } & \text { long period } \\ \text { NEIS } & \text { National Earthquake Information Service } \\ \text { NTS } & \text { Nevada Test Site } \\ \text { NPE } & \text { Non-Proliferation Experiment } \\ \text { PSRF } & \text { Pinedale Seismic Research Facility } \\ \text { SNR } & \text { signal-to-noise ratio } \\ \text { WUS } & \text { western United States }\end{array}$




\section{INTRODUCTION}

Since the dissolution of the Soviet Union, the scenario for monitoring underground nuclear tests has changed. Prior to 1991, the United States was concerned about monitoring nuclear explosions from specific test sites in the Soviet Union to make sure the yield was not above the $150 \mathrm{kT}$ negotiated limit. Today the United States is concerned about "horizontal proliferation", the spread of nuclear weapons to non-nuclear countries. The focus is on monitoring nuclear explosions of small and large yields from anywhere in the world. As nuclear explosions get smaller, the number of earthquakes and industrial explosions of the same size increases dramatically. Discrimination of the small events then becomes more important, and regional monitoring (distances less than $1500 \mathrm{~km}$ ) becomes the best method to detect and identify suspicious events.

Teleseismic monitoring (distances over $1500 \mathrm{~km}$ ) had been the method for monitoring the Soviet Union, because teleseismic discrimination for large magnitude events $\left(m_{b}>4.5\right)$ can be done (cf. Sykes and Evernden, 1982). Seismic waves traveling at teleseismic distances go through the deep interior of the earth which is relatively homogeneous over large distances, and consequently, the teleseismic signals are not difficult to interpret. Regional waves however, are trapped within the Earth's crust and upper mantle where there are large, frequent physical variations. This means that regional signals are complex, and easily influenced by site and path characteristics. In order to effectively monitor at regional distances, we need to learn more about regional wave propagation in various parts of the world. If we have areas where both nuclear explosions and earthquakes have been recorded, we can also test different discrimination techniques to see the effects of crustal variation. Most discrimination techniques were developed for teleseismic data, so we need to learn how well they work at regional distances. This information may then lead to new regional discriminants.

At the Pinedale Seismic Research Facility (PSRF) in western Wyoming, we had an opportunity to look at nuclear explosions from the Nevada Test Site (NTS), western United States (WUS) earthquakes, and the Non-Proliferation Experiment (NPE), a chemical explosion of approximately one kiloton detonated at NTS on September 22, 1993. PSRF is operated by the Air Force Technical Applications Center (AFTAC) and is approximately $7.5^{\circ}-7.6^{\circ}(830-850 \mathrm{~km}$ ) from the northern end of NTS (Figure 1). Sandia National Laboratories installed a Deployable Seismic Verification System (DSVS) at PSRF in the spring of 1990. DSVS was built to monitor a Comprehensive Test Ban Treaty (CTBT) and records data using two seismometers in three frequency bands: $\mathrm{HF}(0.5-50 \mathrm{~Hz}), \operatorname{IP}(0.01-$ $2.5 \mathrm{~Hz})$ and $L P(0.02-0.05 \mathrm{~Hz})$. In the two and one half years that the data was transmitted by satellite to Albuquerque, a good database of events occurring in the western United States was collected. (Appendix 1; Figure 1). Fourteen NTS nuclear explosions were recorded by DSVS, plus four earthquakes that occurred on or close to the test site with NEIS (National Earthquake Information Service) body-wave magnitudes between 3.8 and 5.6. Thirty other WUS earthquakes at distances between 236 and $1290 \mathrm{~km}$ from PSRF 
were also used in the study, along with a DOD explosion from White Sands, NM.

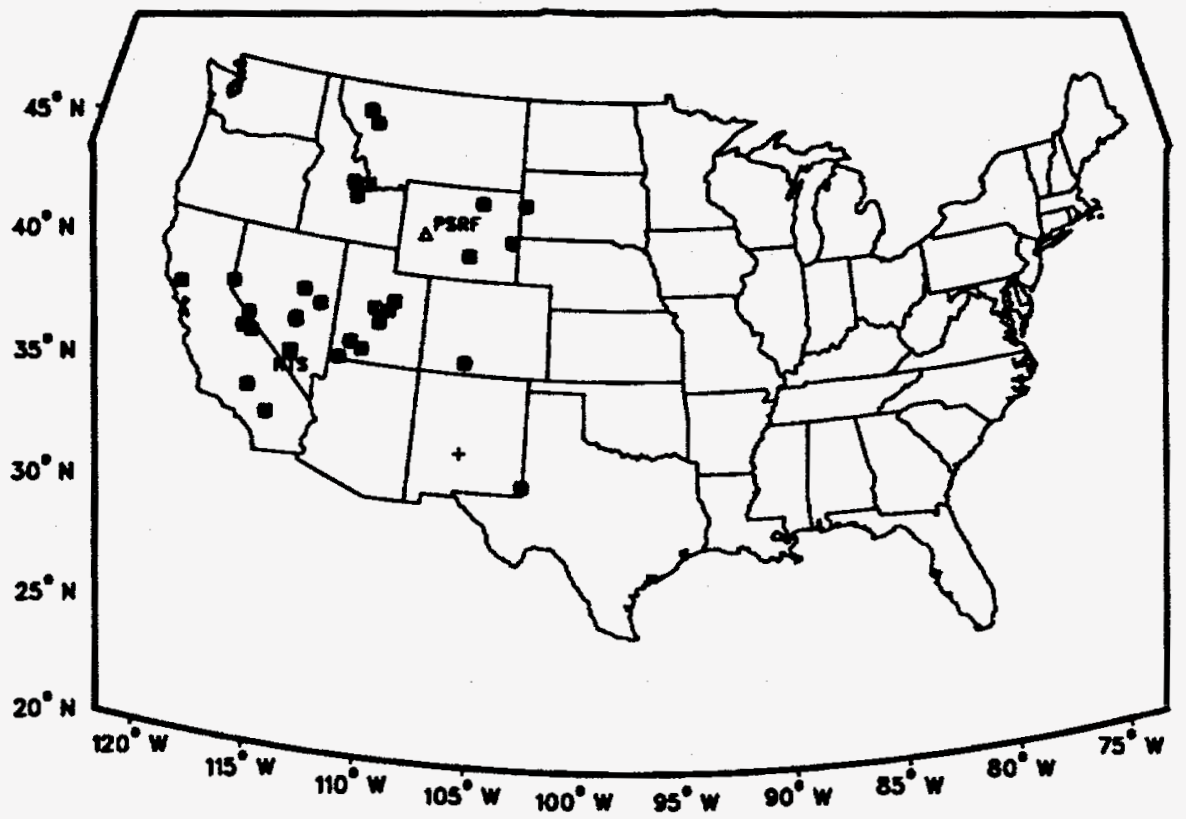

Figure 1: Map of PSRF, NTS and WUS earthquakes used in study.

\section{DISCRIMINATION TECHNIQUES}

The discrimination techniques used with the PSRF data are based on the work by Taylor et al. (1989). They looked at a variety of regional discriminants at the four Lawrence Livermore National Laboratory (LLNL) seismic stations located between 200 and $400 \mathrm{~km}$ from NTS. Four discriminants that gave the best results in the Taylor et al. study were tried at PSRF: $\mathrm{m}_{\mathrm{b}}: \mathrm{M}_{\mathrm{s}}, \mathrm{m}_{\mathrm{b}}: \mathrm{M}_{\mathrm{s}}{ }_{\mathrm{h}}, \log \left(\mathrm{L}_{\mathrm{g}} / \mathrm{P}_{\mathrm{g}}\right)$ and spectral ratios.

$\mathrm{m}_{\mathrm{b}}: \mathrm{M}_{\mathrm{s}}$

The $m_{b}: M_{s}$ discriminant compares the body-wave magnitude $\left(m_{b}\right)$ calculated with the highest zero-to-peak amplitude in the $P_{n}$ wave to the surface-wave magnitude $\left(M_{s}\right)$ calculated with the highest zero-to-peak amplitude in the Rayleigh waves. The theory behind this discriminant is that explosions do not generate as much surface wave energy as earthquakes; for events with the same $m_{b}$, earthquakes will have a larger $M_{s}$. A number of reasons have been proposed for this difference: source dimension, source time function, source mechanism or a combination of the three (Dahlman and Israelson, 1977). This discriminant has been an accepted technique at teleseismic distances since the late 1960s (Pomeroy et al., 1982). Good results at regional distances have been seen by McEvilly and 
Peppin (1972), Peppin and McEvilly (1974) and Taylor et al. (1989). One problem with the discriminant however, is that small magnitude events may have poor Rayleigh wave excitation, so it can be difficult to get reliable $\mathrm{M}_{\mathrm{s}}$ measurements.

At PSRF, $m_{b}$ was calculated using the WUS formula by Evernden (1967):

$$
\mathrm{m}_{\mathrm{b}}=-7.55+1.21 \log (\mathrm{A} / \mathrm{T})+3.68 \log (\Delta)
$$

where $A$ is the highest zero-to-peak amplitude (nm), $T$ is the period (sec) and $\Delta$ is the source to receiver distance $(\mathrm{km})$. The amplitude and period were measured in the $P_{n}$ wave looking in the time window from the initial onset to $6.0 \mathrm{~km} / \mathrm{sec}$ on the vertical trace of the $\mathrm{HF}$ band. The data was low-pass filtered at $4.0 \mathrm{~Hz}$ because all the events in the study had good signal-to-noise at these frequencies. $M_{s}$ was calculated using the formula by Marshall and Basham (1972) which has been corrected to eliminate the variable effects of near distances and propagation paths using a distance correction function, $B$ ' $(\Delta)$, and a period dependent path correction $P(T)$ that normalizes $M_{S}$ to large teleseismic distance 20 -sec values:

$$
\mathrm{M}_{\mathrm{s}}=\log (\mathrm{A})+\mathrm{B}^{\prime}(\Delta)+\mathrm{P}(\mathrm{T})
$$

where $A$ is the zero-to-peak amplitude $(\mathrm{nm}), \Delta$ is source to receiver distance (degrees) and $\mathrm{T}$ is the period (sec). The measured Rayleigh wave amplitude and period were found in the time window $\Delta / 3.1$ to $\triangle 2.8+29$ seconds on unfiltered $L P Z$. For events for which there were no good surface waves, the $M_{s}$ calculated is an upper bound of the noise.

$\mathbf{m}_{\mathbf{b}}: \mathbf{M}_{\mathbf{s}}^{\mathbf{h}}$

Forsyth (1976) found anomalous earthquakes from central Asia that had unusually low $m_{b}: M_{s}$ values. He tried looking at higher-mode Rayleigh waves which, depending upon depth and focal mechanism of the source, could have more energy than the fundamental Rayleigh wave. Forsyth found that $\mathbf{M}_{\mathbf{s}}{ }^{\mathrm{h}}$ works well in central Asia for small events for which it is not possible to obtain a complete spectrum of the fundamental Rayleigh wave. At PSRF, $\mathrm{M}_{\mathrm{s}}{ }^{\mathrm{h}}$ was calculated using Forsyth's formula:

$$
\mathrm{M}_{\mathrm{s}}{ }^{\mathrm{h}}=\log (\mathrm{A})+\mathrm{B}^{\prime}(\Delta)+\log (\mathrm{T} / 10)+\log (7.5)
$$

where $\mathrm{A}$ is the peak-to-peak amplitude $(\mathrm{nm}), \Delta$ is distance (degrees) and $\mathrm{T}$ is the period (sec). The amplitude and period were measured on unfiltered IPZ in the time window of $\Delta$ 4.0 to $\Delta / 3.5$. The distance correction $B^{\prime}(\Delta)$ from Marshall and Basham (1972) is included along with a mode correction, $\log (7.5)$. The mode correction is based on the region of central Asia, but following the work by Taylor et al. (1989), it was used at PSRF since we are looking only at discrimination. The same $m_{b}$ calculated for $m_{b}: M_{s}$ was used for $m_{b}: M_{s} h$. 


\section{$\log \left(\mathrm{L}_{\mathrm{g}} / \mathbf{P}_{\mathrm{g}}\right)$}

There is general agreement in the verification community that the $\log \left(\mathrm{L}_{\mathrm{g}} / \mathrm{P}_{\mathrm{g}}\right)$ discriminant is useful, but the application of the discriminant is disappointing. Different regions of the world behave differently when using $\log \left(\mathrm{L}_{\mathrm{g}} / \mathrm{P}_{\mathrm{g}}\right)$. There is a tendency for the earthquakes to have a larger ratio than nuclear explosions, but the two populations can overlap significantly. This is because regional phases can be strongly dependent on recording site geology (Barker et al., 1981; Leonard et al., 1988). Also scattering of the seismic energy plays an important role in propagation of $\mathrm{L}_{\mathrm{g}}$ and $\mathrm{P}_{\mathrm{g}}$ (Gupta and Blandford, 1983). In order to use this discriminant effectively, a large number of earthquakes and nuclear explosions from a specific region must be examined to get a good idea of how the discriminant works for that region. At PSRF, the maximum peak-to-peak amplitudes for $P_{g}$ and $\mathrm{L}_{\mathrm{g}}$ were measured on HFZ after it was low pass filtered at $10 \mathrm{~Hz}$. $\mathrm{P}_{\mathrm{g}}$ was measured in the time span $\Delta / 6.0$ to $\Delta / 5.2 \mathrm{sec}$. and $\mathrm{L}_{\mathrm{g}}$ was measured in the time span $\Delta / 3.8$ to $\Delta / 3.0 \mathrm{sec}$.

\section{Spectral ratios}

The spectral ratio discriminant is based on the theory that the spectra of earthquakes and explosions have different characteristics. In the western U. S., different authors have shown that earthquakes have more high frequency energy than nuclear explosions of similar magnitude (Murphy and Bennett, 1982; Chael, 1988; Taylor et al., 1988). This result is opposite from what is seen from other parts of the world (Savino et al., 1980; Evernden et al., 1986; Taylor and Marshall, 1987). Different theories such as depth variations in $\mathrm{Q}$ (Taylor et al.,1988) or differences in coupling source radiation from earthquakes and explosions into regional propagation paths (Chael, 1988) have been put forth to explain the differences seen in the WUS. Whatever the reason, however, spectral ratios appear to discriminate between earthquakes and nuclear explosions in the WUS.

To get the best results, spectral ratio measurements need to be made in widely spaced frequency bands. Taylor et al. (1989) found that at the LLNL stations around NTS, the frequency bands of 1 to $2 \mathrm{~Hz}$ and 6 to $8 \mathrm{~Hz}$ worked the best. At PSRF we cannot use a frequency band of 6 to $8 \mathrm{~Hz}$ because for a lot of the events, there is no signal at these frequencies due to attenuation. The two bands used with the DSVS data are 0.4 to $0.6 \mathrm{~Hz}$ measured on IPZ and 4.0 to $6.0 \mathrm{~Hz}$ measured on HFZ. We only looked at $P_{n}$ (initial onset to $\Delta / 6.0$ sec.), because Taylor et al. (1989) found the same results for $P_{n}, P_{g}$ and $L_{g}$. The results were corrected for distance using a first-order distance correction obtained by fitting a line to the log of the spectral ratio versus distance.

\section{RESULTS}

The discrimination techniques were first tried with only the NTS nuclear explosions, the four earthquakes on or near the Test Site, and the NPE. Since these events are all from the same area, we can consider the path effects to PSRF to be similar. Then the rest 
of the earthquakes and DOD explosion are added to see how the discriminants work using events from all over the WUS. The different discriminants were applied to all the data regardless of signal-to-noise. Therefore, some of the results may be measurements of coda noise, rather than signal.

$\mathbf{m}_{\mathbf{b}}: \mathbf{M}_{\mathbf{s}}$

One difficulty with the $m_{b}: M_{s}$ discriminant is that surface waves are not always seen clearly from regional events. There are a number of events that do not have clear surface waves in our data base. Only nuclear explosions with NEIS $m_{b}$ greater than 5.1 have good surface waves except for Floydata (NEIS $m_{b}=4.2$ ). Of the four earthquakes on or near NTS, only the largest has clear Rayleigh waves. In order to see clear Rayleigh waves for the other WUS events, the event has to have a NEIS $m_{b}$ over 4.3 or a local magnitude over 4.1. Exceptions were two earthquakes with $m_{b}=3.3$ and 3.4 that both had good Rayleigh waves. For the majority of events without clear surface waves however, the signal was over the coda noise in the frequency band of interest $(0.02-0.1 \mathrm{~Hz})$. So even if surface waves were not clearly seen for an event, a $\mathrm{M}_{\mathrm{s}}$ was estimated using the highest zero-topeak amplitude in the time span where the Rayleigh waves would be expected. There were six WUS earthquakes that did not have good signal-to-noise in the Rayleigh wave window. For at least these six events, the calculated $M_{s}$ is actually an upper bound of the noise.

Figure $2 \mathrm{a}$ shows the results of the $\mathrm{m}_{\mathrm{b}}: \mathrm{M}_{\mathrm{s}}$ discriminant for the events located on or near NTS. There is a clear separation between the nuclear explosions and earthquakes. When the WUS events are added (Figure 2b), there is still good separation. Only three events fell on the wrong side of the decision line which was determined by visual inspection. The DOD explosion is slightly above the decision line. Since this event was above ground, it is possible that the $\mathrm{P}_{\mathrm{n}}$ energy was not as well coupled to the ground as the underground explosions from NTS. It also took place over $1000 \mathrm{~km}$ from PSRF and has an $\mathrm{m}_{\mathrm{b}}$ (WUS) of only 3.5 .

The two earthquakes on the explosion side of the plot are both located in Wyoming. The $m_{b}$ (WUS) $=3.5$ event is only $236 \mathrm{~km}$ southeast of PSRF. When looking at the $P_{n}$ wave for this earthquake, the signal was above the noise out to $32 \mathrm{~Hz}$. This event had no clear surface waves, and was one of the six events where the $M_{s}$ measurement is an upper bound of the noise. The second event $\left(m_{b}(\right.$ WUS $\left.)=3.3\right)$ is located $422 \mathrm{~km}$ directly east of PSRF. The $P_{n}$ arrival from this earthquake also had signal above the noise over 30 $\mathrm{Hz}$. There were no clear surface waves, although the signal-to-noise in the Rayleigh wave window averaged $10 \mathrm{~dB}$ at frequencies up to $0.07 \mathrm{~Hz}$. The $\mathrm{M}_{\mathrm{s}}$ calculated for both of these earthquakes are probably upper bounds of the noise. 

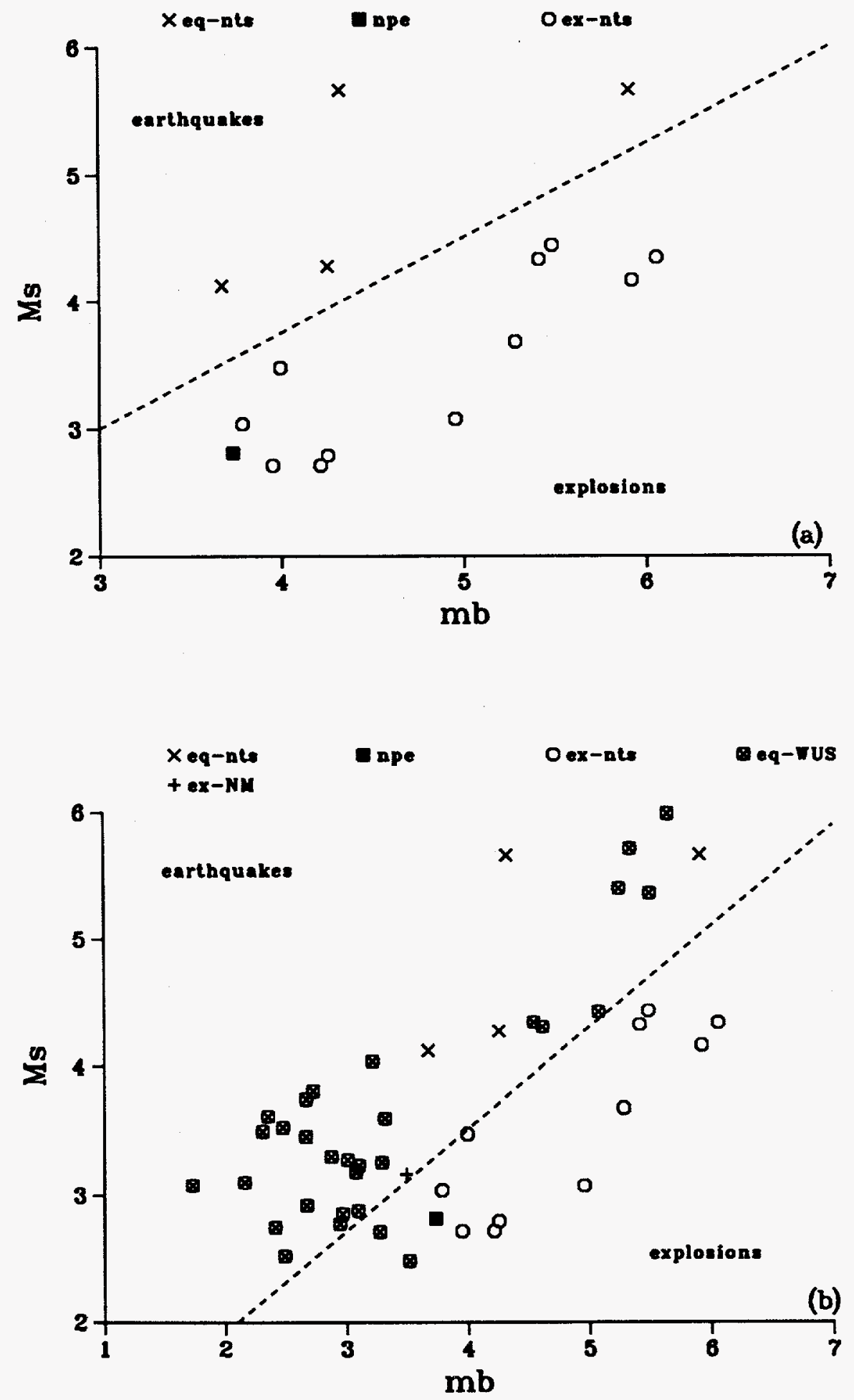

Figure 2: The $m_{b}: M_{s}$ discriminant for (a) NTS events only and (b) all WUS events. 


$$
\mathbf{m}_{\mathbf{b}}: \mathbf{M}_{\mathbf{s}}^{\mathbf{h}}
$$

The $m_{b}: M_{s}{ }^{h}$ technique could be valuable for events with no clear fundamental mode surface waves. A problem can occur if the signal-to-noise is not good enough in the time window where the $\mathrm{M}_{\mathrm{s}}{ }^{\mathrm{h}}$ measurement is made. This time window is just before the $\mathrm{L}_{\mathrm{g}}$ arrival. For this data set, signal-to-noise calculations in the frequency band 0.04 to $1.0 \mathrm{~Hz}$ were made comparing the $\mathrm{M}_{\mathrm{S}}{ }^{\mathrm{h}}$ window to the coda directly in front of the window. Signalto-noise in the $\mathrm{M}_{\mathrm{s}}{ }^{\mathrm{h}}$ window for the NTS explosions are good. In the frequency band between 0.04 and $1.0 \mathrm{~Hz}$, the average span of SNR $>0$ is $0.16 \mathrm{~Hz}$ and the average peak SNR is $6.7 \mathrm{~dB}$. Only $52 \%$ of the earthquakes in the data set have SNR as good as the explosions over the same window. However, the majority have SNR $>0$ for at least a span of $0.08 \mathrm{~Hz}$ with peak SNR over $4.4 \mathrm{~dB}$. Four earthquakes have relatively poor signal-tonoise between 0.04 and $1.0 \mathrm{~Hz}$ in the $\mathrm{M}_{\mathrm{s}}{ }^{\mathrm{h}}$ window. One of these events, $\mathrm{a}_{b}$ (WUS)=3.2 earthquake has no SNR $>0$ in the $\mathrm{M}_{\mathrm{S}}^{\mathrm{h}}$ window. For this earthquake and at least the other three earthquakes with poor $S N R$, the $M_{S}{ }^{h}$ measurement is an upper bound of the noise.

Figure 3a shows the results of the $m_{b}: M_{s}{ }^{h}$ discriminant using the earthquakes on NTS, nuclear explosions and NPE. As with $m_{b}: M_{s}$, there is a clear separation between the earthquake and explosion populations. When the other WUS events are added (Figure $3 \mathrm{~b}$ ), this discriminant does not work as well. For smaller magnitude events $\left(\mathrm{m}_{b}(\mathrm{WUS})<3.5\right)$, the earthquakes cluster on the explosion side of the decision line. The earthquake with no SNR > 0 in the $M_{S}{ }^{h}$ window had the worst results: $M_{S}{ }^{h}=1.85$. The other three earthquakes with poor signal-to-noise are all in the group of events with $m_{b}$ (WUS) $<3.5$. The $M_{s}{ }^{h}$ measurements from these three earthquakes are comparable to similar $m_{b}$ earthquakes that have good signal-to-noise. Unfortunately the major problem with the small magnitude events is that there are no nuclear explosions at the same magnitudes to compare to the earthquakes. It is possible that the explosions would still separate from the earthquakes if both populations shifted. However, it could also be that the two populations merge at these magnitudes. If the second possibility is true, then $m_{b}: M_{s}{ }^{h}$ will not be a good discriminant for the small magnitude events.

There are three earthquakes at $m_{b}$ (WUS) $>4.0$ that fall in with the explosion population. These events do not have much in common, although they were located fairly close together on the $m_{b}: M_{s}$ plot (Figure $2 b$ ). In fact, the $m_{b}$ (WUS)=5.0 earthquake from northern California was located very close to the decision line in Figure $2 b$. This earthquake is a prime example of an event Forsyth (1976) was trying to accommodate with his $\mathrm{M}_{\mathrm{s}}{ }^{\mathrm{h}}$ scale. However, this one earthquake with a low $\mathrm{M}_{\mathrm{s}}$ also has a low $\mathrm{M}_{\mathrm{s}}{ }^{\mathrm{h}}$. 

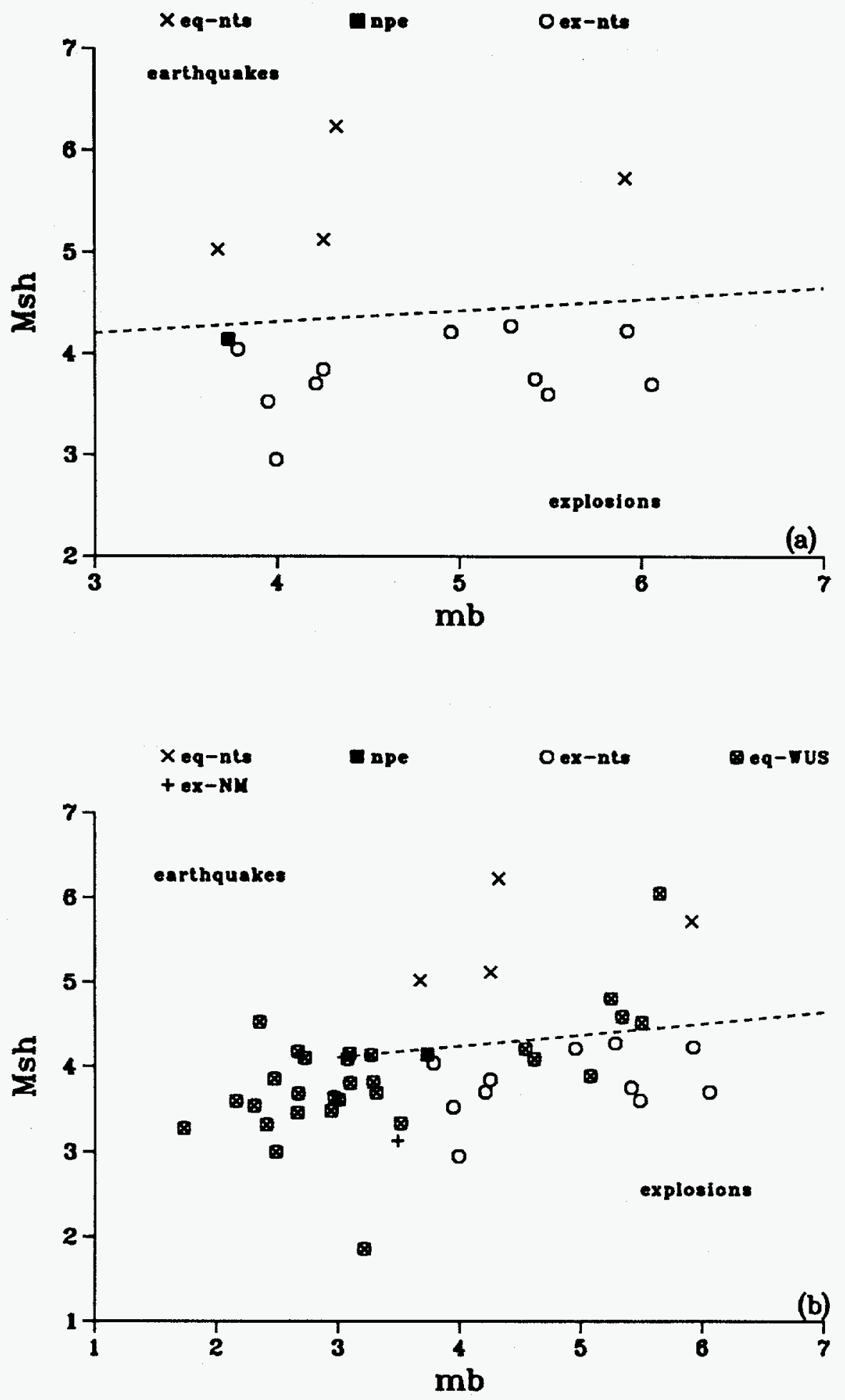

Figure 3: The $m_{b}: M_{s}^{h}$ discriminant for (a) NTS events only and (b) all WUS events. 
$\log \left(\mathbf{L}_{g} / \mathbf{P}_{g}\right)$

The results of the $\log \left(\mathrm{L}_{\mathrm{g}} / \mathrm{P}_{\mathrm{g}}\right)$ discriminant using DSVS data from PSRF is in Figure 4. Only the events on or near NTS are plotted in Figure 4a, and there is some overlap between the earthquakes and explosions. The smallest NTS earthquake $\left(m_{b}(W U S)=3.7\right)$ plots with the explosions. This earthquake is not recorded particularly well at PSRF. In fact, it is difficult to see the $\mathrm{L}_{\mathrm{g}}$ arrival which is why the $\log \left(\mathrm{L}_{\mathrm{g}} / \mathrm{P}_{\mathrm{g}}\right)$ ratio is low. Two nuclear explosions, Distant Zenith and Galena have high ratios (over 0.4). Both of these explosions had shallow depths of burials between 250 and 300 meters, compared to the other tests that averaged depths of burials of 520 meters. The $\mathrm{L}_{\mathrm{g}}$ amplitudes from these two explosions are larger than the $\mathrm{P}_{\mathrm{g}}$ amplitudes. An explanation may be that because the events are shallow, the $P$ energy is not coupled well into the earth, or conversely, the $L_{g}$ energy is well coupled to the earth.

When the rest of the WUS events are added (Figure 4b), the results do not improve. At the smaller magnitudes the ratios of the earthquakes are seen over the entire range, -0.6 to 0.8 . At the higher frequencies there are three earthquakes that plot with the explosions. Two of these earthquakes are from Utah, and have similar azimuths. The closer event has a $\mathrm{P}_{\mathrm{g}}$ amplitude that is bigger than the $\mathrm{L}_{\mathrm{g}}$ amplitude. The other Utah event has $\mathrm{P}_{\mathrm{g}}$ and $\mathrm{L}_{\mathrm{g}}$ amplitudes that are similar. This is also true for the third earthquake that is located in southern New Mexico.

The propagation paths for $\mathrm{P}_{\mathrm{g}}$ and $\mathrm{L}_{\mathrm{g}}$, plus the recording site geology at PSRF influence this site in such a way that the $\log \left(\mathrm{L}_{\mathrm{g}} / \mathrm{P}_{\mathrm{g}}\right)$ discriminant is unsuccessful. Even filtering the data in smaller pass bands $(0.2-4.5 \mathrm{~Hz}, 4-6 \mathrm{~Hz})$ did not have any affect on the results. In other areas of the world where $\log \left(\mathrm{L}_{\mathrm{g}} / \mathrm{P}_{\mathrm{g}}\right)$ discriminant has been found not to work well, such as Scandinavia; $\log \left(\mathrm{L}_{\mathrm{g}} / \mathrm{P}_{\mathrm{n}}\right)$ gives better results (D. Baumgardt, personal communication). $\log \left(\mathrm{L}_{\mathrm{g}} / \mathrm{P}_{\mathrm{n}}\right)$ was tried at PSRF using data low-pass filtered at $10 \mathrm{~Hz}$. The results are seen in Figure 5. The plot for NTS events (Figure 5a) does not change from the $\log \left(\mathrm{L}_{\mathrm{g}} / \mathrm{P}_{\mathrm{g}}\right)$ plot (Figure 4a). The same three events overlap. The two decision lines on the plot are attempts to separate the populations. The upper line seems to work best because it groups all the explosions together.

The $\log \left(\mathrm{L}_{\mathrm{g}} / \mathrm{P}_{\mathrm{n}}\right)$ discriminant using all the WUS events is in Figure $5 \mathrm{~b}$. When all the events are plotted, the $\log \left(\mathrm{L}_{\mathrm{g}} / \mathrm{P}_{\mathrm{n}}\right)$ discriminant works better than the $\log \left(\mathrm{L}_{\mathrm{g}} / \mathrm{P}_{\mathrm{g}}\right)$ (Figure $4 b)$. The $P_{n}$ amplitudes are generally smaller than the $P_{g}$ amplitudes. Earthquakes that did not separate well using $P_{g}$ amplitudes because the $P_{g}$ and $L_{g}$ amplitudes were similar, do separate using $P_{n}$, since most $P_{n}$ amplitudes are smaller than $L_{g}$ amplitudes. There are some earthquakes that still fail using $\log \left(\mathrm{L}_{\mathrm{g}} / \mathrm{P}_{\mathrm{n}}\right)$. Seven of the ten earthquakes at $\mathrm{m}_{\mathrm{b}}$ (WUS) $<4.0$ that fall under the upper decision line are at distances over $700 \mathrm{~km}$ from 

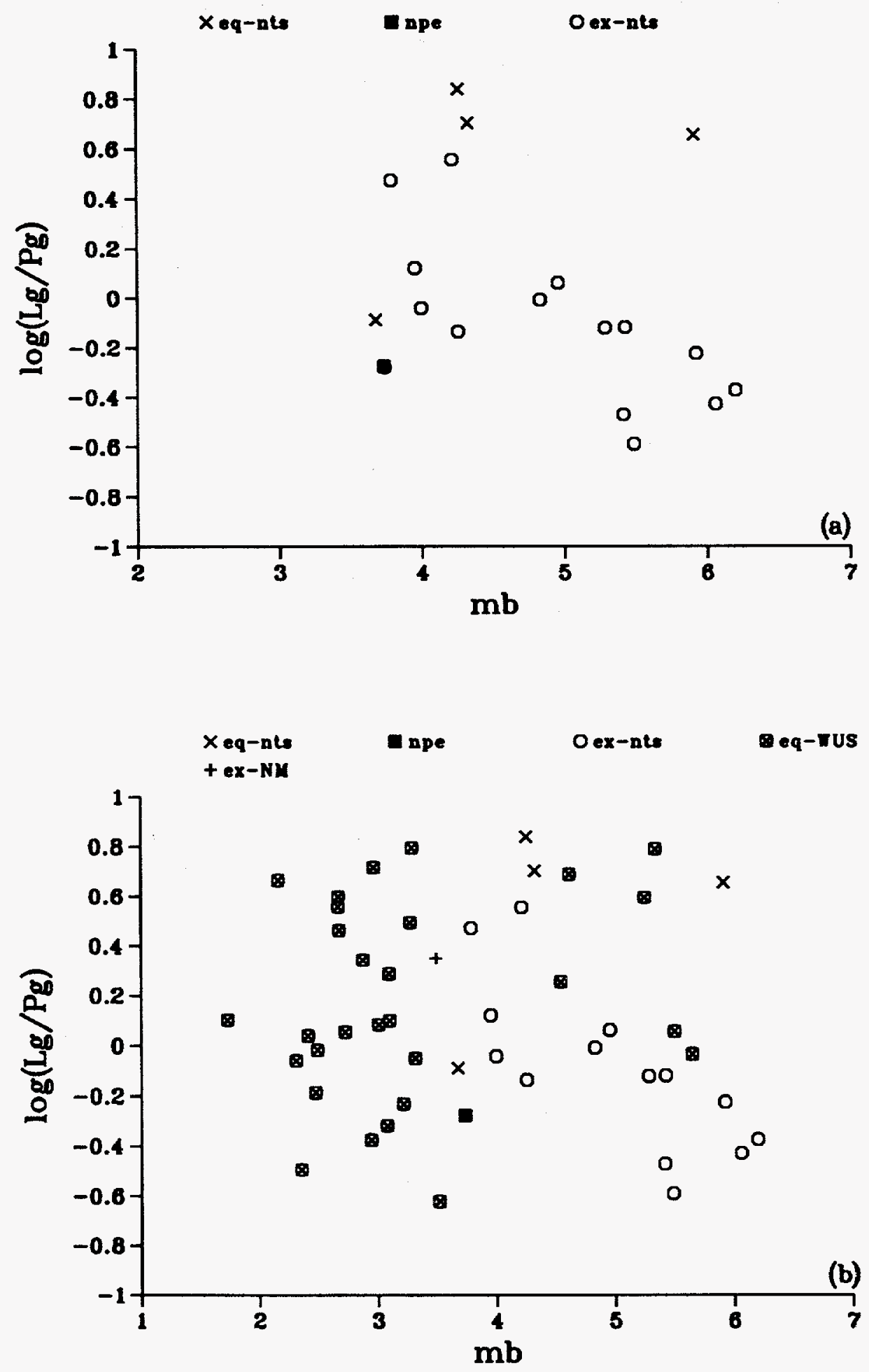

Figure 4: The $\log \left(\mathrm{L}_{\mathrm{g}} / \mathrm{P}_{\mathrm{g}}\right)$ discriminant for (a) NTS events only and (b) all WUS events. 

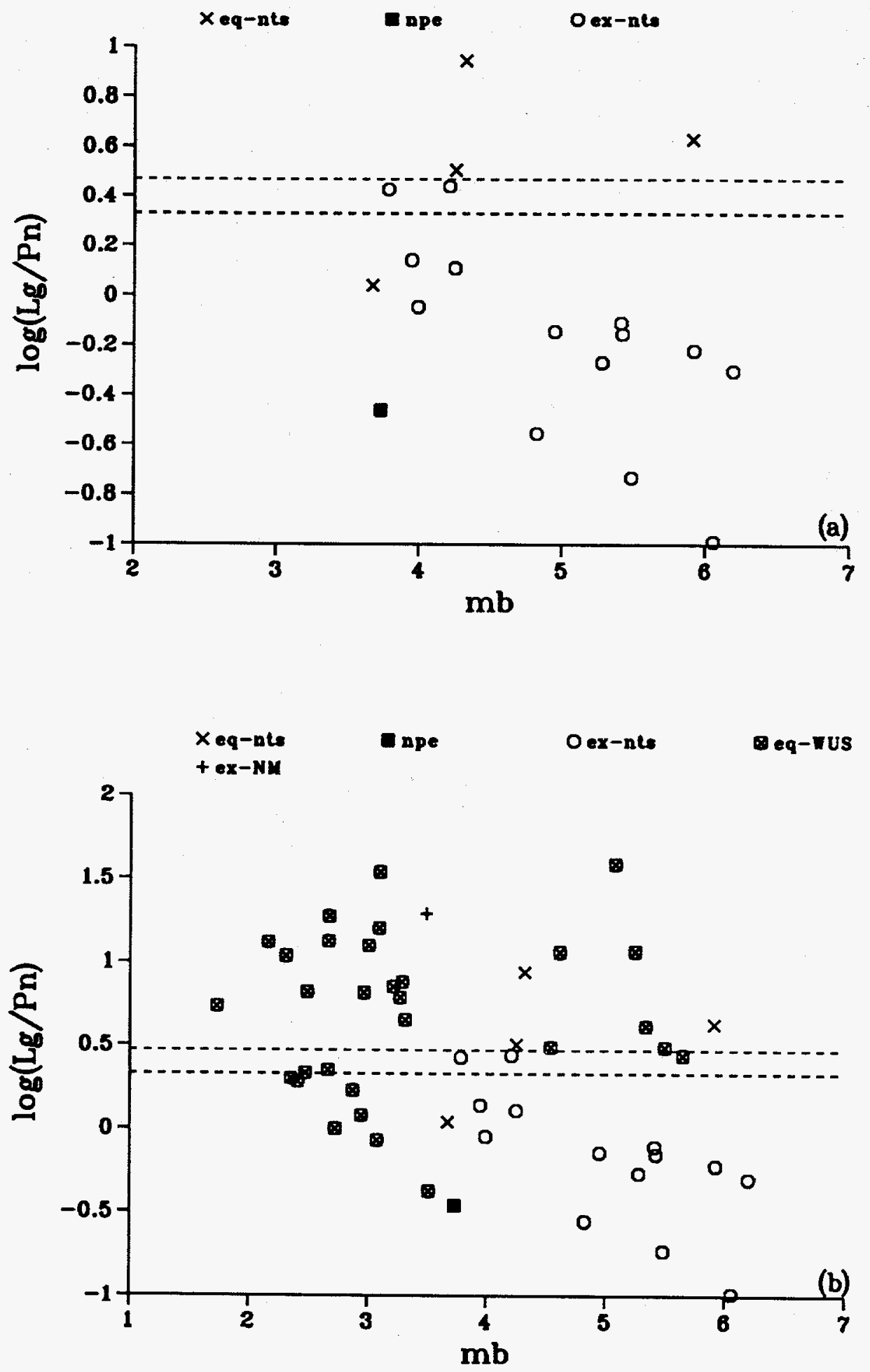

Figure 5: The $\log \left(\mathrm{L}_{\mathrm{g}} / \mathrm{P}_{\mathbf{n}}\right)$ discriminant for (a) NTS events only and (b) all WUS events. 
PSRF. For most of these events the signal is difficult to see without filtering the data, even though there is signal above the noise for both $P_{n}$ and $L_{g}$ arrivals. However the amplitudes calculated for these earthquakes may be more noise than earthquake energy. The discriminant appears to fail for these earthquakes because the $\mathrm{L}_{\mathrm{g}}$ energy has been attenuated and the calculated amplitude is too small. The three other earthquakes at these magnitudes that fail have very good SNR for the $\mathrm{P}_{\mathrm{n}}$ arrival. Two are located in western Idaho $420 \mathrm{~km}$ away from PSRF, and the third is the Wyoming event $236 \mathrm{~km}$ away. The SNR for the $\mathrm{L}_{\mathrm{g}}$ arrival are not as good as the $P_{n}$. These events look more like explosions with the $P_{n}$ amplitudes larger than the $\mathrm{L}_{\mathrm{g}}$ amplitudes. In the NEIS bulletin the three events are classified as shallow earthquakes, but for all three, the depth was restrained at $5 \mathrm{~km}$ by a geophysicist.

\section{Spectral ratios}

The spectral ratio discriminant using frequency bands of $0.4-0.6 \mathrm{~Hz}$ and $4.0-6.0 \mathrm{~Hz}$ are shown in Figure 6. Signal-to-noise ratios were calculated in these bands using the noise before the $\mathrm{P}_{\mathrm{n}}$ arrival. The SNR for the NTS explosions, the NPE and three of the earthquakes on the Test Site are fairly good. The fourth NTS earthquake did not have good SNR between 4.0 and $5.5 \mathrm{~Hz}$. Signal-to-noise ratios for the other WUS events is not always very good. Three earthquakes have no clear signal between 0.4 and $0.6 \mathrm{~Hz}$, and two others had poor SNR in both bands. For at least thirteen WUS events, at least one of the measurements used in to determine the spectral ratio is an upper bound of the noise.

The events from NTS (Figure 6a) are plotted without a distance correction because they are all from a similar location and distance. The events from NTS separate into two populations. Even the earthquake $\left(\mathrm{m}_{\mathrm{b}}(\mathrm{WUS})=4.3\right)$ with poor $\mathrm{SNR}$ in the HF band plots clearly with the earthquake population. A difference between this study and work done by other authors (Murphy and Bennett, 1982; Chael, 1988; Taylor et al., 1988) is that at PSRF the explosions have more energy at higher frequencies than earthquakes of similar magnitudes. At PSRF the higher frequency band is only $4.0-6.0 \mathrm{~Hz}$ because there were a number of events that did not have signal over the noise at frequencies over $6.0 \mathrm{~Hz}$. Taylor et al. (1988) went up to at least $8 \mathrm{~Hz}$, and Chael (1988) was looking at signal at frequencies close to $30 \mathrm{~Hz}$. Another difference between the studies is that the other authors looked at other phases. Chael (1988) found his biggest differences by looking at the $P_{g}$ phase.

Figure $6 \mathrm{~b}$ plots the spectral discriminant for all the WUS events. In this plot the events have been corrected for distance. There is no separation of the explosion and earthquake populations, even at the higher magnitudes. The failure of the discriminant is not due to poor SNR in either band. Four earthquakes with good SNR in both bands have spectral ratios less than 0.1. For example, the Wyoming earthquake $236 \mathrm{~km}$ from PSRF has average SNR of $54.9 \mathrm{~dB}$ in the HF band and $17.1 \mathrm{~dB}$ in the IP band. Yet the spectral ratio for this event is -1.88 . Events with spectral ratios over 0.85 and magnitudes under 3.0 , all have poor SNR in at least one band, yet they appear to be correctly identified by the spectral ratio discriminant. From this plot it appears that the earthquakes located on or 

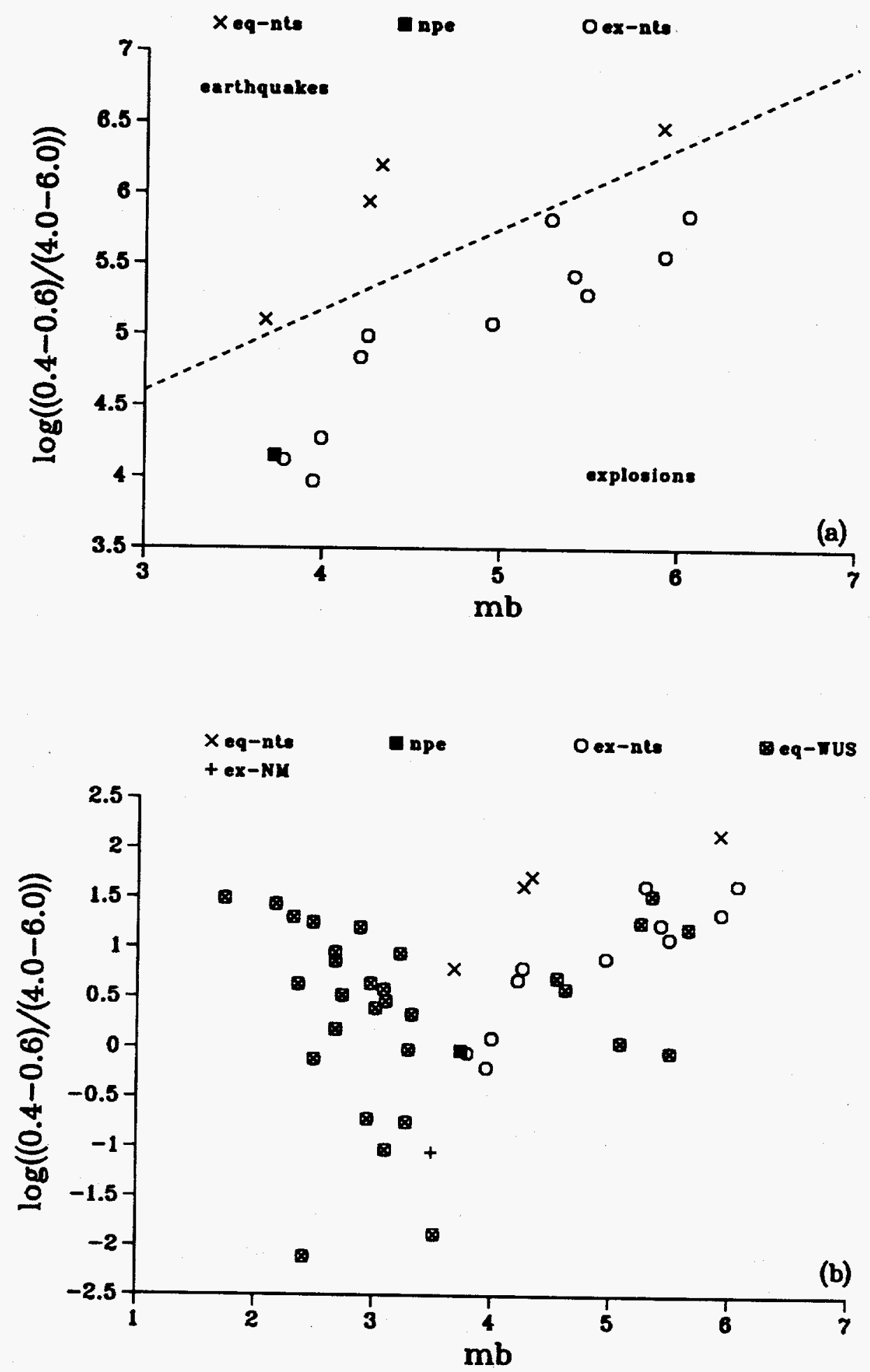

Figure 6: The spectral ratio discriminant for (a) NTS events only and (b) all WUS events. A first order distance correction has been made for the events in (b). 
near NTS are different than the other WUS earthquakes. It could be that the structure at NTS causes differences in how energy is coupled to the earth, or the differences could be due to path effects. Whatever the reason, the spectral ratio discriminant fails at PSRF when events from all around the WUS are included.

\section{DISCUSSION AND CONCLUSIONS}

Five discriminants were applied to fourteen NTS nuclear explosion, four earthquakes on or near NTS, the NPE and 30 WUS events recorded at PSRF. The discriminants are $\mathrm{m}_{\mathrm{b}}: \mathrm{M}_{\mathrm{s}}, \mathrm{m}_{\mathrm{b}}: \mathrm{M}_{\mathrm{s}}{ }^{\mathrm{h}}, \log \left(\mathrm{L}_{\mathrm{g}} / \mathrm{P}_{\mathrm{g}}\right), \log \left(\mathrm{L}_{\mathrm{g}} / \mathrm{P}_{\mathrm{n}}\right)$ and spectral ratios. All the discriminants except for $\log \left(\mathrm{L}_{\mathrm{g}} / \mathrm{P}_{\mathrm{g}}\right)$ worked fairly well at PSRF when just looking at the events from on or near NTS. Because all of these events are from similar locations, the paths to PSRF are considered to be the same. When looking at these events, we are getting a picture of the source differences alone, rather than a combination of source and path differences.

When the other WUS earthquakes and the DOD explosion from White Sands are included, only one of the discriminants shows any promise: $m_{b}: M_{s}$. The $m_{b}: M_{s}{ }^{h}$ discriminant appears to fail at $m_{b}$ (WUS) $<3.5$. Since there are no nuclear explosions at these magnitudes to compare to the earthquakes, we can't be absolutely sure if the discriminant fails. However, the earthquakes at the lower magnitudes cluster on the wrong side of the decision line that was determined using the higher magnitude data. Unfortunately in the world of horizontal proliferation, the smaller magnitude events are the ones we need to be able to discriminate. The spectral ratios also do not work well at PSRF when all the WUS events are included. One of the problems with spectral ratios is that there are many uncertainties is understanding the physical mechanisms behind how this discriminant works. Since there is good separation between earthquakes from NTS and the explosions, it appears path effects may adversely affect spectral ratios.

$\log \left(\mathrm{L}_{\mathrm{g}} / \mathrm{P}_{\mathrm{n}}\right)$ is a better discriminant that $\log \left(\mathrm{L}_{\mathrm{g}} / \mathrm{P}_{\mathrm{g}}\right)$, but both fail to discriminate all WUS earthquakes. The smallest earthquake on NTS falls in with the explosions, along with ten other WUS earthquakes. In all these cases the $\mathrm{L}_{\mathrm{g}}$ arrival is not recorded well at PSRF, so the $\mathrm{L}_{\mathrm{g}}$ amplitude is not as large as would be expected. Two small NTS explosions have high $\log \left(\mathrm{L}_{\mathrm{g}} / \mathrm{P}_{\mathrm{n}}\right)$ values. The $\mathrm{L}_{\mathrm{g}}$ amplitudes are larger than expected for these two relatively shallow NTS shots. These two discriminants were the only ones that misidentified events from NTS, indicating that path effects are not the only reason these discriminants fail. Processes involved with generation of the $\mathrm{L}_{\mathrm{g}}$ and $\mathrm{P}_{\mathrm{g}}$ waves must influence the amount of energy seen at PSRF. Path effects, such as attenuation of the seismic energy, are also seen to play a role for events from around the WUS at large distances from PSRF. 
The only discriminant that appears to work at PSRF for all WUS events is $m_{b}: M_{s}$. The proposed theories for how this discriminant work are all based on the properties of the source. Path effects should not affect the results, and this seems to be true at PSRF. Even events where Rayleigh waves were not recorded well at PSRF separated correctly into the two populations. Only two earthquakes from eastern Wyoming plot on the explosion side. One of these earthquakes is $240 \mathrm{~km}$ southeast of PSRF and was recorded very well by DSVS. The character of the signal suggests that although the NEIS bulletin implies the event is an earthquake, it may very well be an explosion. In Figure 7 the suspect event (top) is compared to another Wyoming earthquake $312 \mathrm{~km}$ northeast of PSRF (bottom). The bottom earthquake has the characteristic earthquake character: the $\mathrm{L}_{\mathrm{g}}$ arrival has a higher amplitude than the $\mathrm{P}$ waves. The suspect event has more of an explosion signature; the $\mathrm{P}$ wave has more energy than the $\mathrm{L}_{\mathrm{g}}$ wave. The suspect earthquake is located in a coal mining region of Wyoming, so it is possible that this event is actually an explosion.
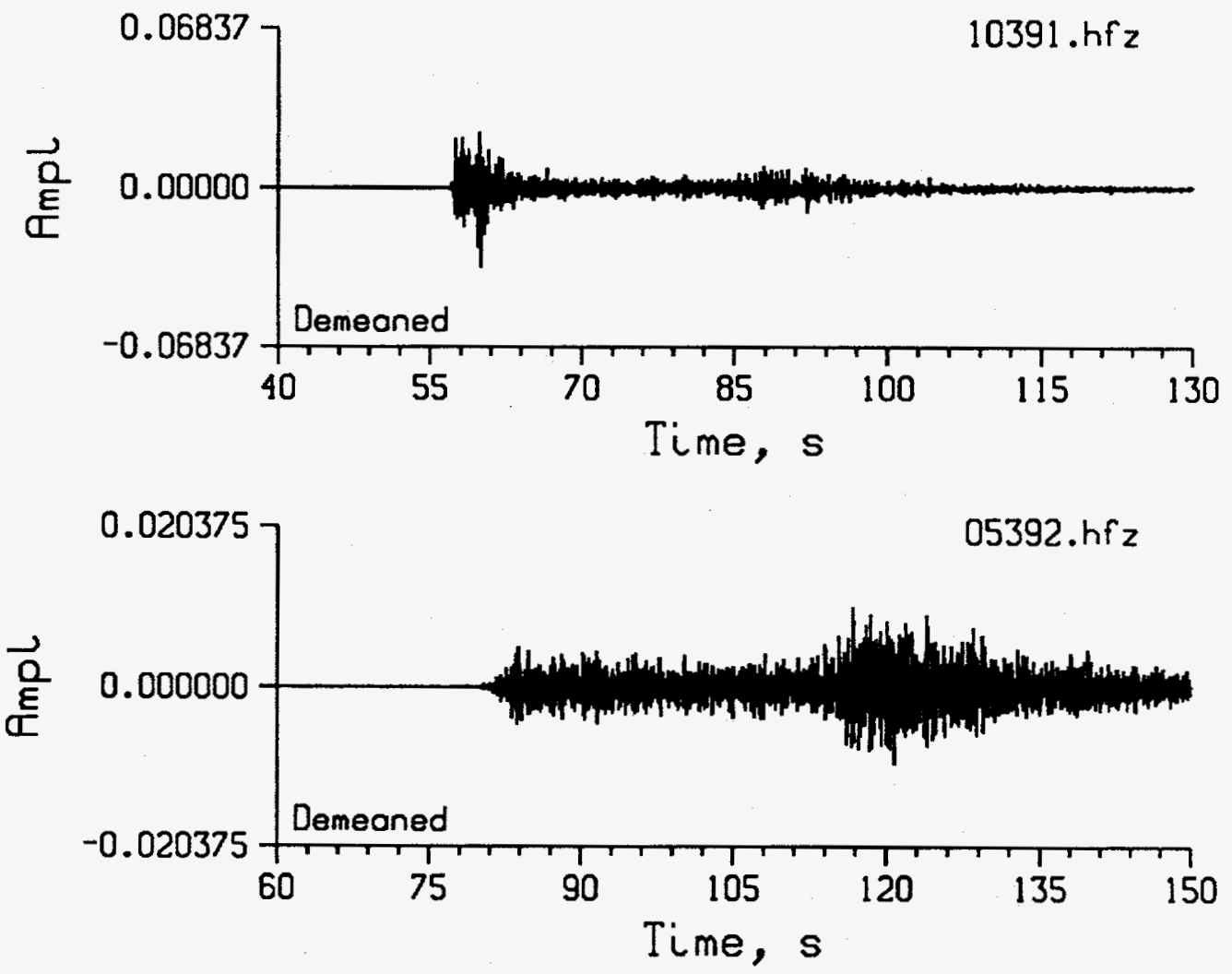

Figure 7: Two WUS events from Wyoming. Both are considered to be earthquakes, but the top event has more of a characteristic signal of an explosion. 
When discriminating between events from one specific region, NTS, so that the geologic structure at the source and receiver are more or less the same and the seismic energy is traveling along one path, most of the discriminants work well. Only $\log \left(\mathrm{L}_{\mathrm{g}} / \mathrm{P}_{\mathrm{g}}\right)$ and $\log \left(\mathrm{L}_{\mathrm{g}} / \mathrm{P}_{\mathfrak{n}}\right)$ have a misidentified event: the smallest NTS earthquake. However, when events from all over the WUS are included so that seismic energy is traveling along a number of different paths, there is much more variability in the performance of the discriminants. We found that neither the short period discriminants $\left(\log \left(\mathrm{L}_{\mathrm{g}} / \mathrm{P}_{\mathrm{g}}\right), \log \left(\mathrm{L}_{\mathrm{g}} / \mathrm{P}_{\mathrm{n}}\right)\right.$, and spectral ratios), nor $m_{b}: M_{s}^{h}$ perform well at PSRF. The problems are the most apparent for small magnitude events, the events that are important to discriminate at regional distances. Research needs to be done to understand the mechanisms behind how these discriminants work at regional distances. Once the theory is known, it may be possible to eliminate some of the variability in the results that is now seen.

\section{REFERENCES}

Barker, B. W., Z. A. Der, and C. P. Mrazek, (1981). The effect of crustal structure on the regional phases Pg and Lg at the Nevada Test Site, J. Geophys. Res., 86, 1686-1700.

Chael, E. P., (1988). Spectral discrimination of NTS explosions and earthquakes in the southwestern United States using high-frequency regional data, Geophys. Res. Lett., 15, 625-628.

Dahlman, O. and H. Israelson, (1977). Monitoring Underground Nuclear Explosions, Elsevier Scientific Publishing Company, Amsterdam, 440pp.

Evernden, J. F., (1967). Magnitude determination of regional and near-regional distances in the United States, Bull. Seis. Soc. Am., 57, 591-639.

Evernden, J. F., C. B. Archambeau, and E. Cranswick (1986). An evaluation of seismic decoupling and underground nuclear test monitoring using high-frequency seismic data, Rev. Geophys., 24, 143-215.

Forsyth, D. W., (1976). Higher mode Rayleigh waves as an aid to seismic discrimination, Bull. Seis. Soc. Am., 66, 827-841.

Gupta, I. N. and R. R. Blandford, (1983). A mechanism for generation of short-period transverse motion from explosions, Bull. Seis. Soc. Am., 73, 571-591.

Leonard, M. A., L. R. Johnson, and T. V. McEvilly, (1988). Regional studies with broadband data, DARPA/AFGL Seismic Research Proceedings, 251-258.

Marshall P. D. and P. W. Basham, (1972). Discrimination between earthquakes and underground explosions employing an improved Ms scale, Geophys. J. R. astr. Soc., 28 , 431-458.

McEvilly, T. V. and W. A. Peppin, (1972). Source characteristics of earthquakes, explosions and afterevents, Geophys. J. 31, 67-82.

Murphy, J. R. and J. J. Bennett, (1982). A discrimination analysis of short-period regional seismic data recorded at Tonto Forest Observatory, Bull. Seis. Soc. Am., 72, 13511366

Peppin, W. A. and T. V. McEvilly, (1974). Discrimination among small-magnitude events on Nevada Test Site, Geophys J., 37, 227-243. 
Pomeroy, P. W., W. J. Best, and T. V. McEvilly, (1982). Test ban treaty verification with regional data -- A review, Bull. Seis. Soc. Am., 72, S89-S129.

Savino, J. M., C. B. Archambeau, and J. F. Masso, (1980). VFM discrimination results from a ten station network, Systems, Science and Software, VSC-TR-81-29, La Jolla, California, 111pp.

Sykes, L. R., and J. F. Evernden, (1982). The verification of a comprehensive nuclear test ban, Sci. Am. 247, 47-55.

Taylor, S. R. and P. D. Marshall, (1987). Spectral discrimination between Soviet explosions and earthquakes using UK array data, (abstract), EOS, Trans. Am. Geophys. Union, 44, 1364.

Taylor, S. R., N. W. Sherman and M. D. Denny, (1988). Spectral discrimination between NTS explosions and western United States earthquakes at regional distances, Bull. Seis. Soc. Am., 78, 1563-1579.

Taylor, S. R., M. D. Denny, E. S. Vergino and R. E. Glaser, (1989). Regional discrimination between NTS explosions and western U. S. earthquakes, Bull. Seis. Soc. Am., 79, 1142-1176. 


\section{APPENDIX}

List of events used in study 


\begin{tabular}{|c|c|c|c|c|}
\hline NAME & DATE & LOCATION & DISTANCE & $\begin{array}{c}\text { NEIS } \\
\mathrm{m}_{\mathrm{b}}\end{array}$ \\
\hline Bullion $\wedge$ & 13-Jun-90 & $37.262 \mathrm{~N} 116.420 \mathrm{~W}$ & $846.7 \mathrm{~km}$ & 5.7 \\
\hline Mineral Quarry ^ & 25-Jul-90 & $37.207 \mathrm{~N} 116.214 \mathrm{~W}$ & $839.3 \mathrm{~km}$ & 4.7 \\
\hline Houston $\wedge$ & 14-Nov-90 & $37.227 \mathrm{~N} 116.371 \mathrm{~W}$ & $846.7 \mathrm{~km}$ & 5.4 \\
\hline Bexar & 04-Apr-91 & $37.296 \mathrm{~N} 116.313 \mathrm{~W}$ & $837.6 \mathrm{~km}$ & 5.6 \\
\hline Montello & 16-Apr-91 & $37.245 \mathrm{~N} 116.442 \mathrm{~W}$ & $849.4 \mathrm{~km}$ & 5.4 \\
\hline Floydata & 15-Aug-91 & $37.087 \mathrm{~N} 116.002 \mathrm{~W}$ & $837.6 \mathrm{~km}$ & 4.2 \\
\hline Hoya & 14-Sep-91 & $37.226 \mathrm{~N} 116.428 \mathrm{~W}$ & $850.1 \mathrm{~km}$ & 5.5 \\
\hline Distant Zenith & 19-Sep-91 & $37.236 \mathrm{~N} 116.166 \mathrm{~W}$ & $834.1 \mathrm{~km}$ & 4.0 \\
\hline Lubbock & 18-Oct-91 & $37.063 \mathrm{~N} 116.045 \mathrm{~W}$ & $842.1 \mathrm{~km}$ & 5.2 \\
\hline Bristol & 26-Nov-91 & $37.096 \mathrm{~N} 116.070 \mathrm{~W}$ & $840.6 \mathrm{~km}$ & 4.6 \\
\hline Junction & 26-Mar-92 & $37.272 \mathrm{~N} 116.360 \mathrm{~W}$ & $842.3 \mathrm{~km}$ & 5.5 \\
\hline Galena & 23-Jun-92 & $37.124 \mathrm{~N} 116.031 \mathrm{~W}$ & $836.0 \mathrm{~km}$ & $3.9 *$ \\
\hline Hunter's Trophy & $18-S e p-92$ & $37.207 \mathrm{~N} 116.210 \mathrm{~W}$ & $839.1 \mathrm{~km}$ & 4.4 \\
\hline Divider & 23-Sep-92 & $37.021 \mathrm{~N} 115.998 \mathrm{~W}$ & $843.1 \mathrm{~km}$ & 4.4 \\
\hline NPE & $22-\operatorname{Sep}-93$ & $37.126 \mathrm{~N} 116.159 \mathrm{~W}$ & $839.6 \mathrm{~km}$ & 4.1 \\
\hline Earthquake \#1 & 29-Jun-92 & $36.705 \mathrm{~N} 116.293 \mathrm{~W}$ & $886.9 \mathrm{~km}$ & 5.6 \\
\hline Earthquake \#2 & 29-Jun-92 & $36.686 \mathrm{~N} 116.238 \mathrm{~W}$ & $885.6 \mathrm{~km}$ & 4.3 \\
\hline Earthquake \#3 & 29-Jun-92 & $36.756 \mathrm{~N} 116.236 \mathrm{~W}$ & $885.2 \mathrm{~km}$ & 3.8 \\
\hline Earthquake \#4 & 28-Jun-92 & $36.419 \mathrm{~N} 116.780 \mathrm{~W}$ & $939.0 \mathrm{~km}$ & 4.4 \\
\hline
\end{tabular}

$\wedge$ no IP or LP data for this event $\quad *$ local magnitude 


\begin{tabular}{|c|c|c|c|c|}
\hline STATE & DATE & LOCATION & DISTANCE & $\begin{array}{c}\text { NEIS } \\
\mathrm{m}_{\mathrm{b}}\end{array}$ \\
\hline Utah & 22-Mar-91 & $37.816 \mathrm{~N} 112.995 \mathrm{~W}$ & $623.9 \mathrm{~km}$ & 3.2 \\
\hline California & 24-Mar-91 & $37.645 \mathrm{~N} 118.945 \mathrm{~W}$ & $979.5 \mathrm{~km}$ & 3.3 \\
\hline Wyoming & 13-Apr-91 & $42.031 \mathrm{~N} 106.857 \mathrm{~W}$ & $236.6 \mathrm{~km}$ & 3.2 \\
\hline California & 04-May-91 & $37.552 \mathrm{~N} 118.432 \mathrm{~W}$ & $951.2 \mathrm{~km}$ & $4.1 *$ \\
\hline Colorado & 10-May-91 & $37.466 \mathrm{~N} 106.594 \mathrm{~W}$ & $641.9 \mathrm{~km}$ & $3.4 *$ \\
\hline Nevada & 17-Мау-91 & $39.194 \mathrm{~N} 114.960 \mathrm{~W}$ & $603.6 \mathrm{~km}$ & $3.2 *$ \\
\hline New Mexico \% & 20-Jun-91 & $33.619 \mathrm{~N} 106.475 \mathrm{~W}$ & $1053.2 \mathrm{~km}$ & $3.5 *$ \\
\hline Montana & 18-Jul-91 & $47.753 \mathrm{~N} 113.841 \mathrm{~W}$ & $646.7 \mathrm{~km}$ & 3.5 \\
\hline California/Nevada & 12-Aug-91 & $38.220 \mathrm{~N} 118.750 \mathrm{~W}$ & $927.2 \mathrm{~km}$ & 4.4 \\
\hline Utah & 21-Aug-91 & $39.364 \mathrm{~N} 111.878 \mathrm{~W}$ & $426.6 \mathrm{~km}$ & $3.3 *$ \\
\hline South Dakota ${ }^{\wedge}$ & 05-Nov-91 & $44.350 \mathrm{~N} 103.750 \mathrm{~W}$ & $499.2 \mathrm{~km}$ & $2.5 *$ \\
\hline Utah & 21-Dec-91 & $37.567 \mathrm{~N} 112.322 \mathrm{~W}$ & $625.2 \mathrm{~km}$ & 3.6 \\
\hline New Mexico & 02-Jan-92 & $32.347 \mathrm{~N} 103.124 \mathrm{~W}$ & $1290.0 \mathrm{~km}$ & 4.7 \\
\hline Idaho & 24-Jan-92 & $43.999 \mathrm{~N} 113.893 \mathrm{~W}$ & $373.6 \mathrm{~km}$ & 2.7 \\
\hline Wyoming & 22-Feb-92 & $44.324 \mathrm{~N} 106.317 \mathrm{~W}$ & $312.5 \mathrm{~km}$ & $2.9 *$ \\
\hline Idaho & 07-Mar-92 & $44.530 \mathrm{~N} 114.125 \mathrm{~W}$ & $416.0 \mathrm{~km}$ & $3.8 *$ \\
\hline Montana & 21-Mar-92 & $47.267 \mathrm{~N} 113.295 \mathrm{~W}$ & $579.1 \mathrm{~km}$ & 3.7 \\
\hline Idaho & 22-Mar-92 & $44.582 \mathrm{~N} 114.185 \mathrm{~W}$ & $422.8 \mathrm{~km}$ & $4.3 *$ \\
\hline Nevada & 24-Mar-92 & $39.425 \mathrm{~N} 119.924 \mathrm{~W}$ & $944.5 \mathrm{~km}$ & $3.4 *$ \\
\hline Utah & 24-Jun-92 & $38.783 \mathrm{~N} 111.554 \mathrm{~W}$ & $474.9 \mathrm{~km}$ & $4.4 *$ \\
\hline California & 09-Jul-92 & $34.239 \mathrm{~N} 116.837 \mathrm{~W}$ & $1140.4 \mathrm{~km}$ & 5.6 \\
\hline Utah & 11-Jul-92 & $39.322 \mathrm{~N} 111.123 \mathrm{~W}$ & $406.1 \mathrm{~km}$ & 3.9 \\
\hline California & 11-Jul-92 & $35.210 \mathrm{~N} 118.066 \mathrm{~W}$ & $1116.4 \mathrm{~km}$ & 5.3 \\
\hline Nevada & 16-Jul-92 & $38.323 \mathrm{~N} 116.159 \mathrm{~W}$ & $745.6 \mathrm{~km}$ & $3.1 *$ \\
\hline Nevada & 17-Jul-92 & $38.387 \mathrm{~N} 116.120 \mathrm{~W}$ & $738.3 \mathrm{~km}$ & $3.1 *$ \\
\hline
\end{tabular}




\begin{tabular}{|l|l|l|l|l|}
\hline \multicolumn{1}{|c|}{ STATE } & DATE & \multicolumn{1}{c|}{ LOCATION } & DISTANCE & $\begin{array}{c}\text { NEIS } \\
\mathrm{m}_{\mathrm{b}}\end{array}$ \\
\hline \hline Idaho & 28 -Aug-92 & $44.583 \mathrm{~N} 113.323 \mathrm{~W}$ & $363.4 \mathrm{~km}$ & 3.4 \\
\hline Utah & $02-$ Sep-92 & $37.090 \mathrm{~N} 113.472 \mathrm{~W}$ & $715.0 \mathrm{~km}$ & 5.8 \\
\hline California & $19-$ Sep-92 & $38.863 \mathrm{~N} 122.793 \mathrm{~W}$ & $1194.3 \mathrm{~km}$ & 4.6 \\
\hline Wyoming & $02-$ Nov-92 & $42.740 \mathrm{~N} 104.389 \mathrm{~W}$ & $421.7 \mathrm{~km}$ & $3.0^{*}$ \\
\hline Nevada & 10 -Dec-92 & $39.682 \mathrm{~N} 115.956 \mathrm{~W}$ & $636.1 \mathrm{~km}$ & $3.2 *$ \\
\hline Utah & $18-$ Dec-92 & $39.729 \mathrm{~N} 110.838 \mathrm{~W}$ & $355.5 \mathrm{~km}$ & 3.1 \\
\hline
\end{tabular}

\% DOD explosion

$\wedge^{\wedge}$ rockburst

* local magnitude 


\section{Distribution}

US Department of Energy

Office of International Security Affairs

Attn: M. Koontz

L. Casey

D. Breding

Forrestal Bldg. IS-20

1000 Independence Ave. SW

Washington DC 20585

Air Force Technical Applications Center

Attn: F. Pillotte (TT)

Lt. Col. M. Winchester (TTS)

Cpt. S. Doran (TTS)

M. Baker (TTS)

V. Hsu (TTR)

G. Roth (TTR)

N. Yacoub (TTR)

1030 S. Highway A1A

Patrick AFB, FL 32925-3002

Los Alamos National Laboratory

Attn: S. Taylor

B. Stump

P. O. Box 1663

Los Alamos, NM 87545

US Department of Energy

Nevada Field Office

Attn: J. O'Donnell

P. O. Box 98578

Las Vegas, NV 89193-8518

Advanced Research Projects Agency

Attn: R. Alewine

$$
\text { A. Ryall }
$$

Nuclear Monitoring Research Office 1400 Wilson Blvd.

Arlington, VA 22209

Center for Seismic Studies

Attn: G. Gustoffson

R. Blandford (AFTAC)

1300 North 17th Street, Suite 1450

Arlington, VA 22209
Lawrence Livermore National Lab.

Attn: M. Denny

F. Followell

W. Hannon

K. Nakanishi

J. Zucca

P.O. Box 808

Livermore, CA 94550

USGS-Albuquerque Seismological Laboratory

Attn: B. Hutt

Bldg. 10002

Kirtland AFB, NM 87115

IRIS Headquarters

Attn: D. Simpson

R. Butler

1616 N. Fort Myer Dr. Suite 1440

Arlington, VA 22209

MS 0655 P. B. Herrington, 9236

MS 0655 D. B. Carr, 9236 (5)

MS 0655 E. P. Chael, 9236

MS 0655 J. P. Claassen, 9236

MS 0655 B. H. Corbell, 9236

MS 0750 M. C. Walck, 6116

MS 0750 C. J. Young, 6116

MS 0970 T. A. Sellers, 9200

MS 0979 L. S. Walker, 9204

MS 1159 H. D. Garbin, 9311

MS 9018 Central Technical Files 8523-2

MS 0899 Technical Library, 13414 (7)

MS 0619 Technical Publications 13416

MS 0100 Document Processing for DOE/OSTI, 7613-2 (10) 